NEWS

\title{
India's drug problem
}

\section{Chemists show how waste-water contamination affects ecosystem.}

Waste flowing out of a treatment plant near Hyderabad in India pollutes the region's waters with some of the highest levels of pharmaceuticals ever detected in the environment. In a paper being released online this week, researchers in Sweden report how this effluent has serious adverse effects on the development of tadpoles and zebrafish ${ }^{1}$.

The findings raise concerns for the health of wildlife and ecosystems in the region, as well as underscoring little-studied potential effects on human health.

"The volume of drug production in that valley is overwhelming the system," says Stan Cox,
"The government has not monitored for drugs being released into the environment." and other chemicals. But although Patancheru is also home to numerous drug companies, the government has not monitored for drugs being released into the environment.

In 2007 , however, a team led by environmental scientist Joakim Larsson of the University of Gothenburg in Sweden published results from one waste-treatment facility, Patancheru Enviro Tech Ltd (PETL) $)^{2}$. Around 90 companies in the region that manufacture active pharmaceutical ingredients, or assemble final drug products, send their waste to PETL. With permission, Larsson's team sampled the waste exiting the plant; they found drugs including the a researcher at the Land Institute in Salina, Kansas. "Even though they have good [environmental] laws on the books, they're being swamped by the production."

For several years, the National Geophysical Research Institute in Hyderabad and the country's Central Pollution Control Board in Delhi have monitored heavy metal and other pollutants around the town of Patancheru, which is home to factories producing solvents antibiotic ciprofloxacin, at concentrations of up to 31,000 micrograms per litre, and the antihistamine cetirizine, at up to 1,400 micrograms per litre. The team estimated that the amount of ciprofloxacin entering the river from the plant could amount to up to 45 kilograms a day - the equivalent of 45,000 daily doses, says Larsson.

In new work, he and co-workers exposed tadpoles and zebrafish embryos to diluted PETL effluent, equivalent to river water downstream

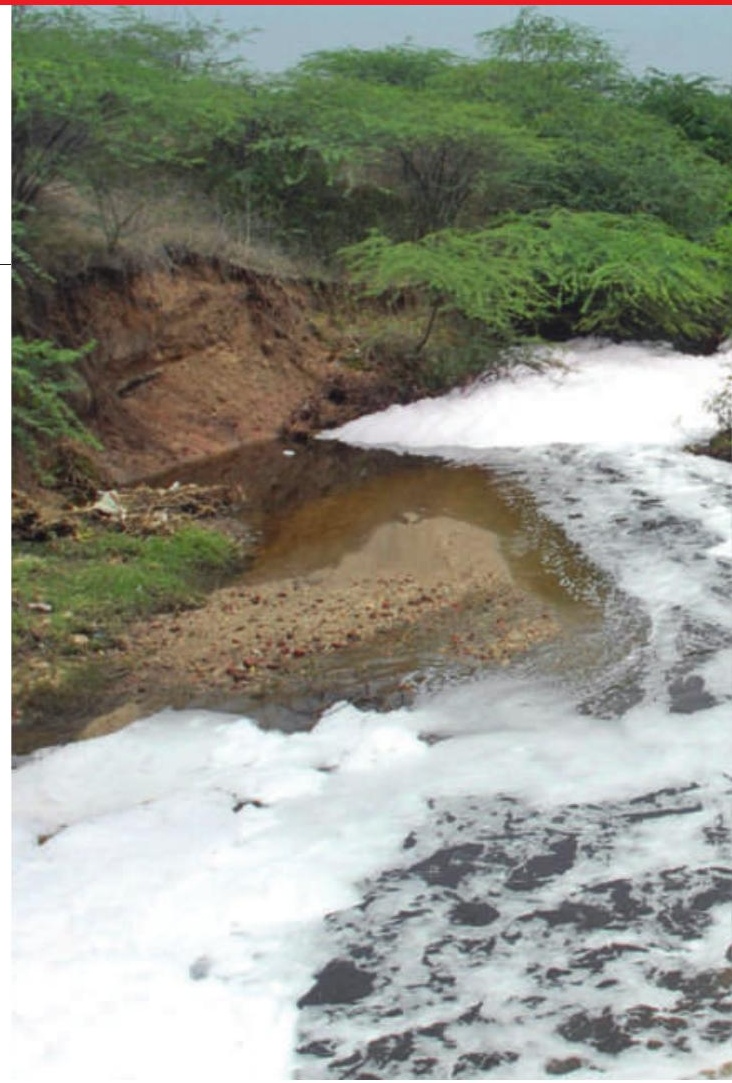

of the plant. At the lowest concentration tested - equivalent to 1,500 cubic metres of effluent diluted in 750,000 cubic metres of river water, or a $0.2 \%$ concentration - the tadpoles experienced $40 \%$ reduced growth compared with controls. And at concentrations of $8-16 \%$, zebrafish embryos lost colour and movement within two days of fertilization, among other developmental effects.

Larsson's team has also found drugs in

\section{French scientists revolt against government reforms}

University lecturers and researchers in France began a national strike on 2 February over a draft decree that would change their job descriptions and procedures for promotion.

The row has brought to a head simmering resentment among many researchers over ongoing broader reforms of research and higher education. It has been further fuelled by President Nicolas Sarkozy's criticisms of the country's researchers in a fiery speech last week.

The government's decree seems, at first glance, fairly innocuous. For the first time, evaluations of university researchers will include their contributions to teaching and university governance, and not be based solely on their research. Universities will also be given the power to change how much time staff spend on teaching and research.
So why has the decision provoked such a vocal and widespread outcry? One reason is that university researchers are used to being assessed nationally. The new policy, which is in line with the government's overall goal of giving universities greater autonomy, transfers that responsibility to the university president and board.

Scientists fear that cash-strapped universities might cut research time and force them to do more teaching, at a time when posts are being cut. In an open letter co-authored by Albert Fert, a 2007 Nobel laureate in physics from the University of Paris-Sud, top academics last week expressed worries that the changes would give university administrators too much control over scientists' work, and risk "clientship and localism".

Such concerns reflect the fact that French scientists generally trust the established

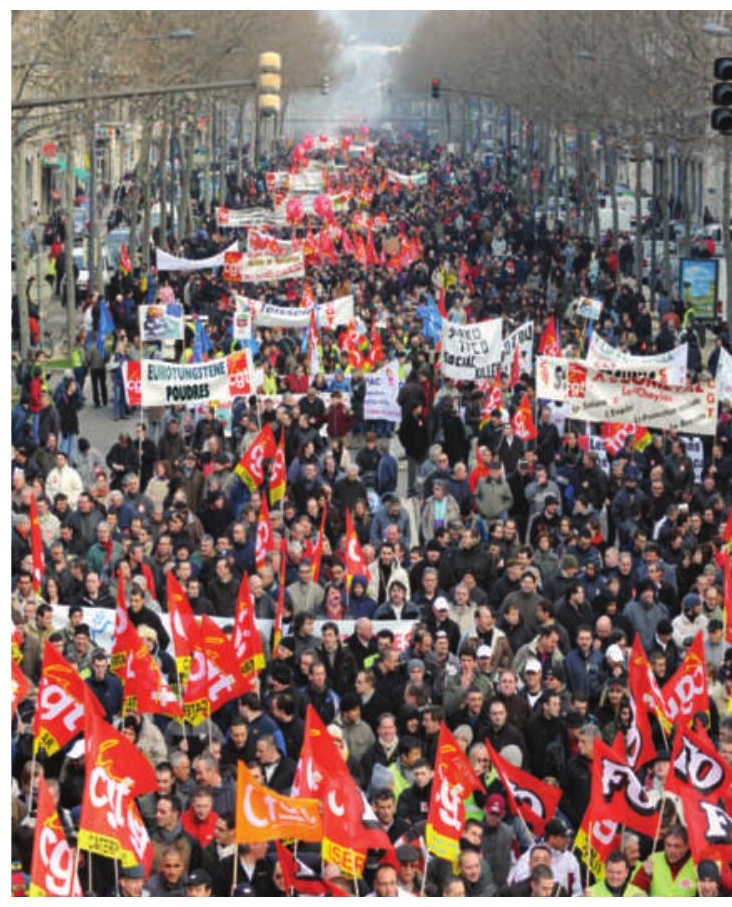

Strikes have swept across France. 
